\title{
Integration of Stochastic Programming and Factorial Design for Optimal Reservoir Operation
}

\author{
J. B. $\mathrm{Li}^{*}$ \\ Environmental Engineering Program, University of Northern British Columbia, Prince George, BC V2N 4Z9, Canada
}

\begin{abstract}
In this study, the reservoir operating rules for satisfying reliable water releases under uncertain inflows and water demands were developed. This development was based on a chance-constrained programming model associated with a factorial design measure for examining interactions among various impact factors. The reservoir inflows and water demands in different operating seasons were of normal distribution with known means and variances. The minimum cost of water releases from the reservoir was achieved by keeping minimum storage, maintaining sufficient flood and drought control capacities, achieving water demands of users, and satisfying releases to downstream channel with acceptable reliabilities. The complex interrelationships among water releases, initial reservoir storage, and reliability level were revealed through the developed model. This proposed approach would offer an improved measure for reservoir operation and management under uncertainty.
\end{abstract}

Keywords: Chance-constrained modeling, factorial design, operation, optimization, reservoir, stochastic, uncertainty

\section{Introduction}

The system analysis techniques have been widely applied to water resources planning and management over the past decades. In terms of reservoir planning and operation practices, there has been much attention on developing and applying a variety of optimization models (Wurbs, 1993). Typical reservoir systems are usually subject to constraints of continuity assumptions and various conditions for regulating reservoir storage and release variables (Reznixek \& Cheng, 1991). Due to the complexities of reservoir systems, a number of uncertainties exist in the related modeling parameters, such as water demands, future costs, and inflow levels. These uncertainties may result in significant impacts on system predictions and the related decisions on system operation and management (Jenkins \& Lund, 2000). As a result, it is recognized that the reservoir optimization modeling should seriously take uncertainties into consideration for ensuring more reliable system planning and decision robustness.

A number of inexact optimization models were developed to account for such uncertainties during the past years (Xu et al., 1997), such as stochastic programming, stochastic dynamic programming, and fuzzy programming. In stochastic dynamic programming (SDP), inflows of the reservoir are considered as the Markov processes. The related decision is usually made to maximize the expected value of the sum of immediate and future returns, and the algorithm has to be solved backwards (Umamahesh \& Sreenivasulu, 1997). The challenge of SDP locates that it is usually associated with difficulties in data availability and solution efforts, especially

\footnotetext{
* Corresponding author: li@unbc.ca
}

when there are more than two state variables (Ravikumar \& Venugopal, 1998; Dos Santos \& Marino, 2002). Fuzzy programming involves fuzzy constraints and/or objectives with the uncertain parameters and/or relationships being treated as fuzzy sets. A decision is then defined as the intersection of the membership function corresponding to the maximized realization of fuzzy goals and constraints (Russell \& Campbell, 1996). As a result, the decision is obtained by applying the max-min convolution operator to maximize the minimum membership value, with the effect of balancing the degree to which the objective is achieved while the constraints have also to be satisfied (Hulsurkar et al., 1997; Jairaj $\&$ Vedula, 2000). As a whole, the fuzzy programming provides a convenient approach for optimizing complex reservoir systems associated with low-quality information where the uncertainty cannot be represented adequately by probability theory (Liu, 2001).

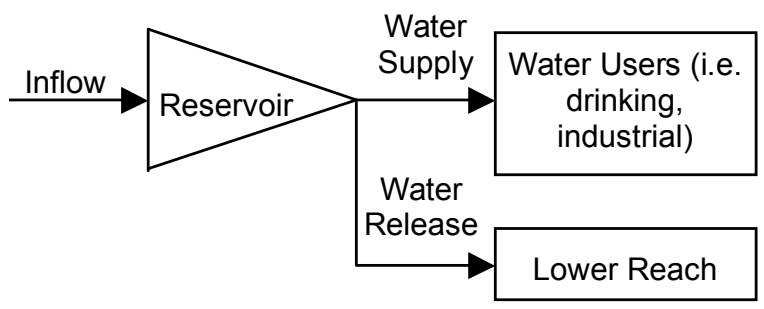

Figure 1. The study reservoir system.

When the system information uncertainty can be characterized by probability distribution, the stochastic program- 
ming may provide an effective tool for system optimization under uncertainty. Among various stochastic approaches, the chance-constrained programming can incurporate stochasticity of input parameters within a linear programming formulation. This approach admits random data variations and permits constraint violations up to specified probability limits (Duffuaa, 1991; Morgan et al., 1993). The probabilistic constraints, with the unknown random variables replaced by their equivalent counterparts derived from known probability distributions under a certain reliability level, can then be converted to deterministic constraints. However, the application of this approach to reservoir operation is challenged by the difficulties in relating probability distributions of input variables to those of release and storage variables, as well as in identifying suitable reliability levels for the related probabilistic constraints to be satisfied (Paudyal \& Das Gupta, 1991; Reznixek \& Cheng, 1991; Rangarrajan \& Simonovic, 1999). As a result, this study is to develop the reservoir operating rules for satisfying reliable water releases under uncertain inflows and water demands by using chanceconstrained programming. The impacts of system reliability level and initial reservoir storage, as well as their interactions, are examined through a factorial design analysis. The complex interrelationships among water releases, initial reservoir storage, and reliability level can then be revealed through implementing the developed model based on a set of reliability levels and initial reservoir storages.

\section{Methodology}

Figure 1 shows a single reservoir system. It supplies water for drinking and industrial users in the watershed, and releases regulated flows to the lower reach. The total reservoir capacity is $C$. The unit cost of supplying water to water users and releasing water to the lower reach are $d_{i}$ and $e_{i}$, respectively, for season $i$ ( $i=1$ for winter, 2 for spring, 3 for summer, and 4 for autumn).

The objective of reservoir operation is to minimize the total costs for water supply and water releases. The related variables include (Reznixek \& Cheng, 1991):

(a) Decision variables:

$R_{l i}$ : water supply from the reservoir to water users at the end of period $i$,

$R_{2 i}$ : releases from the reservoir to the lower reach at the end of period $i$

(b) Parameters:

$F C_{i}$ : flood control storage of the reservoir at the end of period $i$,

$D C_{i}$ : drought control storage of the reservoir at the end of period $i$,

$M R_{i}$ : minimum required release to the lower reach at the end of period $i$,

$M S_{i}$ : minimum required storage of the reservoir at the end of period $i$;

(c) Random variables:
$\tilde{S}_{i}$ : random reservoir storage at the end of period $i$,

$\tilde{X}_{i}$ : random inflow of the reservoir at the end of period $i$,

$\tilde{D}_{i}$ : random minimum water demand of water users from the reservoir at the end of period $i$.

If the seasonal discount rate is $j$, then the reservoir operation problem can be formulated as follows:

$\operatorname{Min} \quad Z=\sum_{i=1}^{4}\left[\frac{d_{i}}{(1+j)^{i}}\left(R_{1 i}\right)+\frac{e_{i}}{(1+j)^{i}}\left(R_{2 i}\right)\right]$

subject to

$\tilde{S}_{i}=S_{i-1}+\tilde{X}_{i}-R_{1 i}-R_{2 i} \quad \forall i$

$\operatorname{Prob}\left(\tilde{S}_{i} \geq M S_{i}\right) \geq \alpha_{1 i} \quad \forall i$

$\operatorname{Prob}\left(C-\tilde{S}_{i} \geq F C_{i}\right) \geq \alpha_{2 i} \quad \forall i$

$\operatorname{Prob}\left(\tilde{S}_{i} \geq D C_{i}\right) \geq \alpha_{3 i} \quad \forall i$

$\operatorname{Prob}\left(R_{1 i} \geq \tilde{D}_{i}\right) \geq \alpha_{4 i} \quad \forall i$

$R_{2 i} \geq M R_{i} \quad \forall i$

$R_{1 i}, R_{2 i} \geq 0 \quad \forall i$

where constraint (1b) is a continuity equation; constraint (1c) states that the reservoir storage should not be less than the minimum level as required for recreation and amenity with a probability of $\alpha_{l i}$; constraint (1d) is about the capacity for flood retention being greater than the flood control storage with a probability of $\alpha_{2 i}$; constraint (1e) states that the reservoir storage should be greater than the drought control demand $\left(\alpha_{3 i}\right)$; constraint (1f) is for satisfaction of water demands of the water users $\left(\alpha_{4 i}\right)$; constraint $(1 \mathrm{~g})$ is about the minimum lower-reach release required for dilution, channel regulation and other purposes; and constraint (1h) is for non-negativity definitions.

The above model requires specification of initial storage $S_{0}$. Constraint (1c) for the first time period can be expressed as follows by using the continuity equation (1b) (Reznixek \& Cheng, 1991):

$\operatorname{Prob}\left(S_{0}+\tilde{X}_{1}-R_{11}-R_{21} \geq M S_{1}\right) \geq \alpha_{11}$

The following constraint can then be obtained by rearranging (2):

$\operatorname{Prob}\left(M S_{1}+R_{11}+R_{21}-S_{0} \leq \tilde{X}_{1}\right) \geq \alpha_{11}$

According to Hulsurkar et al. (1997) and Mohammed (2000), the above constraint can be converted to: 
$M S_{1}+R_{11}+R_{21}-S_{0} \leq F_{X_{1}}^{-1}\left(1-\alpha_{11}\right)$

where $F_{X_{1}}^{-1}\left(1-\alpha_{11}\right)$ is the inverse of the cumulative distribution function evaluated at $\left(1-\alpha_{11}\right)$ for random variable $\tilde{X}_{1}$.

The minimum storage constraint $(1 \mathrm{c})$ for the second time period contains two random events $\tilde{X}_{1}$ and $\tilde{X}_{2}$ which originnate from the double recursive substitution of continuity equation (1b). The equivalent of this constraint at the second time period can then be expressed as:

$$
\begin{aligned}
\operatorname{Prob} & {\left[M S_{2}+\left(R_{11}+R_{21}\right)+\left(R_{12}+R_{22}\right)-S_{0} \leq \tilde{X}_{1}+\tilde{X}_{2}\right] } \\
& \geq \alpha_{12}
\end{aligned}
$$

The above constraint can then be replaced by:

$$
\begin{gathered}
M S_{2}+\left(R_{11}+R_{21}\right)+\left(R_{12}+R_{22}\right)-S_{0} \\
\leq F_{X_{1}+X_{2}}^{-1}\left(1-\alpha_{12}\right)
\end{gathered}
$$

where $F_{X_{1}+X_{2}}^{-1}\left(1-\alpha_{12}\right)$ is the inverse of the cumulative distribution function of the sum of random events $\tilde{X}_{1}$ and $\tilde{X}_{2}$ evaluated at $\left(1-\alpha_{12}\right)$.

Subsequently, the minimum storage constraint (1c) for the $T$-th time period contains the inflow random events of all $T$ time periods. Therefore, the deterministic equivalent of minimum storage constraint for the $T$-th time period can be written as follows:

$$
M S_{T}+\sum_{i=1}^{T}\left(R_{1 i}+R_{2 i}\right)-S_{0} \leq F_{X_{1}+\ldots-X_{T}}^{-1}\left(1-\alpha_{1 T}\right)
$$

where $F_{X_{1}+\ldots+X_{T}}^{-1}\left(1-\alpha_{1 T}\right)$ is the inverse of the cumulative distribution function of the sum of random events $X_{1}, X_{2}, \ldots$, $X_{\mathrm{T}}$ evaluated at $\left(1-\alpha_{1 T}\right)$.

Flood control constraint (1d), drought control constraint (1e), and water supply constraint (1f), can be transformed to their deterministic equivalents for the $T$-th time period in a similar manner as follows:

$$
\begin{aligned}
& C-S_{0}-F C_{T}+\sum_{i=1}^{T}\left(R_{1 i}+R_{2 i}\right) \geq F_{X_{1}+\ldots+X_{T}}^{-1}\left(\alpha_{2 T}\right) \\
& D C_{T}+\sum_{i=1}^{T}\left(R_{1 i}+R_{2 i}\right)-S_{0} \leq F_{X_{1}+\ldots+X_{T}}^{-1}\left(1-\alpha_{3 T}\right) \\
& R_{1 T} \geq F_{D_{T}}^{-1}\left(\alpha_{4 T}\right)
\end{aligned}
$$

Assume that $\tilde{X}_{i}$ and $\tilde{D}_{i}$ are independent random variables that follow normal distribution with known means and standard deviations. Let $\mathrm{E}\left(X_{i}\right)$ and $\sigma\left(X_{i}\right)$ denote the mean and standard deviation of random variable $\tilde{X}_{i}$, while $\mathrm{E}\left(D_{\mathrm{i}}\right)$ and $\sigma\left(D_{i}\right)$ denote the mean and standard deviation of the random variable $\tilde{D}_{i}$. If $K_{\alpha_{i j}}$ represents the value of a standard normal variable at which $F\left(K_{\alpha_{i j}}\right)=\alpha_{i j}$, then the inverse of the cumulative distribution functions can be expressed as follows:

$$
\begin{gathered}
F_{X_{1}+\ldots+X_{T}}^{-1}\left(1-\alpha_{1 T}\right)=E\left(X_{1}\right)+\ldots+E\left(X_{T}\right)+ \\
K_{\left(1-\alpha_{1 T}\right)} \sqrt{\left[\sigma\left(X_{1}\right)\right]^{2}+\ldots+\left[\sigma\left(X_{T}\right)\right]^{2}} \\
F_{X_{1}+\ldots+X_{T}}^{-1}\left(\alpha_{2 T}\right)=E\left(X_{1}\right)+\ldots+E\left(X_{T}\right)+ \\
K_{\alpha_{2 T}} \sqrt{\left[\sigma\left(X_{1}\right)\right]^{2}+\ldots+\left[\sigma\left(X_{T}\right)\right]^{2}} \\
F_{X_{1}+\ldots+X_{T}}^{-1}\left(1-\alpha_{3 T}\right)=E\left(X_{1}\right)+\ldots+E\left(X_{T}\right) \\
+K_{\left(1-\alpha_{3 T}\right)} \sqrt{\left[\sigma\left(X_{1}\right)\right]^{2}+\ldots+\left[\sigma\left(X_{T}\right)\right]^{2}} \\
F_{D_{T}}^{-1}\left(\alpha_{4 T}\right)=E\left(D_{T}\right)+K_{\alpha_{4 T}} \sigma\left(D_{T}\right)
\end{gathered}
$$

Therefore, the stochastic programming problem for reservoir operation as stated in (1) will be equivalent to the following deterministic linear programming problem:

Min $\quad Z=\sum_{i=1}^{4}\left[\frac{d_{i}}{(1+j)^{i}}\left(R_{1 i}\right)+\frac{e_{i}}{(1+j)^{i}}\left(R_{2 i}\right)\right]$

subject to

$$
\begin{array}{rl}
M S_{T} & +\sum_{i=1}^{T}\left(R_{1 i}+R_{2 i}\right)-S_{0} \leq E\left(X_{1}\right)+\ldots \\
& +E\left(X_{T}\right)+K_{\left(1-\alpha_{1 T}\right)} \sqrt{\left[\sigma\left(X_{1}\right)\right]^{2}+\ldots+\left[\sigma\left(X_{T}\right)\right]^{2}} \\
C- & S_{0}-F C_{T}+\sum_{i=1}^{T}\left(R_{1 i}+R_{2 i}\right) \geq E\left(X_{1}\right)+\ldots \\
& +E\left(X_{T}\right)+K_{\alpha_{2 T}} \sqrt{\left[\sigma\left(X_{1}\right)\right]^{2}+\ldots+\left[\sigma\left(X_{T}\right)\right]^{2}} \\
& \\
D C_{T}+\sum_{i=1}^{T}\left(R_{1 i}+R_{2 i}\right)-S_{0} \leq E\left(X_{1}\right)+\ldots \\
\quad+E\left(X_{T}\right)+K_{\left(1-\alpha_{3 T}\right)} \sqrt{\left[\sigma\left(X_{1}\right)\right]^{2}+\ldots+\left[\sigma\left(X_{T}\right)\right]^{2}} \\
R_{1 T} \geq & E\left(D_{T}\right)+K_{\alpha_{4 T}} \sigma\left(D_{T}\right) \\
R_{2 T} \geq & M R_{T} \\
R_{1 T}, R_{2 T} \geq 0 & 1,2,3,4 \\
T= &
\end{array}
$$


Table 1. Parameters of Reservoir Operation (unit: million $\mathrm{m}^{3}$ )

\begin{tabular}{|c|c|c|c|c|c|c|c|}
\hline Parameter & Mean & \multicolumn{2}{|c|}{ Standard deviation } & Parameter & \multicolumn{2}{|l|}{ Mean } & Standard deviation \\
\hline $\mathrm{X}_{1}$ & 3.0 & & & $\mathrm{D}_{1}$ & 0.8 & & 0.3 \\
\hline $\mathrm{X}_{2}$ & 3.5 & & & $\mathrm{D}_{2}$ & 1.5 & & 0.3 \\
\hline $\mathrm{X}_{3}$ & 2.0 & & & $\mathrm{D}_{3}$ & 2.0 & & 0.3 \\
\hline $\mathrm{X}_{4}$ & 2.5 & & & $\mathrm{D}_{4}$ & 1.0 & & 0.3 \\
\hline Parameter & Value & Parameter & Value & Parameter & Value & Parameter & Value \\
\hline $\mathrm{FC}_{1}$ & 1.0 & $\mathrm{DC}_{1}$ & 1.0 & $\mathrm{MS}_{1}$ & 1.0 & $\mathrm{MR}_{1}$ & 0.3 \\
\hline $\mathrm{FC}_{2}$ & 0.8 & $\mathrm{DC}_{2}$ & 1.4 & $\mathrm{MS}_{2}$ & 1.0 & $\mathrm{MR}_{2}$ & 0.3 \\
\hline $\mathrm{FC}_{3}$ & 0.0 & $\mathrm{DC}_{3}$ & 1.8 & $\mathrm{MS}_{3}$ & 1.0 & $\mathrm{MR}_{3}$ & 0.3 \\
\hline $\mathrm{FC}_{4}$ & 0.5 & $\mathrm{DC}_{4}$ & 1.2 & $\mathrm{MS}_{4}$ & 1.0 & $\mathrm{MR}_{4}$ & 0.3 \\
\hline
\end{tabular}

Table 2. Combinations of Factors in the $2^{2}$ Factorial Design

\begin{tabular}{llllll}
\hline Set No. & Reliability Level & Initial Storage (MCM) & Set No. & Reliability Level & Initial Storage (MCM) \\
\hline 1 & 0.6 & 1.5 & 3 & 0.6 & 4.5 \\
2 & 0.88 & 1.5 & 4 & 0.88 & 4.5 \\
\hline
\end{tabular}

Table 3. Estimated Effects on Water Supply and Release

\begin{tabular}{lllllllll}
\hline Factor & $\mathrm{R}_{11}$ & $\mathrm{R}_{12}$ & $\mathrm{R}_{13}$ & $\mathrm{R}_{14}$ & $\mathrm{R}_{21}$ & $\mathrm{R}_{22}$ & $\mathrm{R}_{23}$ & $\mathrm{R}_{24}$ \\
\hline Average & 1.0145 & 1.7145 & 2.2145 & 1.2145 & 1.5355 & 1.4395 & 0.3 & 0.6375 \\
A & 0.277 & 0.277 & 0.277 & 0.277 & 0.046 & -0.078 & 0 & -0.337 \\
B & 0 & 0 & 0 & 0 & 2.471 & 0.529 & 0 & -0.001 \\
AB & 0 & 0 & 0 & 0 & 0.046 & -0.046 & 0 & 0.001 \\
\hline
\end{tabular}

\section{Case Study}

The developed chance-constrained model is applied to a reservoir operation problem under uncertainty. The study reservoir system is shown in Figure 1, with the reliability levels for different constraints in different seasons being assumed to be identical (i.e., $\alpha_{\mathrm{ij}}=\alpha$ ). The unit costs $d_{i}$ and $e_{i}$ for different seasons are 8 and 4, respectively; and the reservoir capacity is 5 million $\mathrm{m}^{3}(\mathrm{MCM})$. The seasonal discount rate is $2.5 \%$. The other related parameters are listed in Table 1.

\section{Result Analysis}

In order to test the sensitivities of reliability level $(\alpha)$ and initial reservoir storage $\left(\mathrm{S}_{0}\right)$ to the decisions of reservoir operation, as well as to examine the interactions between these two parameters, a set of 4 factorial design experiments are implemented based on the $2^{2}$ factorial design. Table 2 lists the combinations of factor settings in the design. The developed chance-constrained programming model is then implemented for each combination.

The main effects and interactive effects are quantified based on the Yates's Algorithm (Box et al., 1978). Table 3 lists the magnitudes of main and interactive effects of the 2 factors, where factors A and B represent reliability and initial reservoir storage, respectively. It is indicated that the system reliability is the only critical factor that has the main effect on water supply to the water users. In comparison, the initial storage will not significantly affect the decision of water supply to the users. In terms of the impacts on water releases to the lower reach, the initial reservoir storage has significant main effect in winter and spring, but negligible effect in summer and autumn. These are due to fact that inflows in winter and spring are higher than those in summer and autumn. The interactive effects of reliability level and initial storage in winter and spring are close to the main effects of reliability level, indicating that the main contribution for this effect is the factor of initial storage. Besides, the main effect of system reliability is significant in autumn, and the negative effect means that increase of reliability will result in decrease of water release.

In order to examine the complex interactions among water release, initial reservoir storage and reliability level, a series of modeling implementations are conducted under a set of reliability and initial reservoir storage levels. Figure 2 shows the relationship between optimal water supply to the water users in different seasons under different reliability levels and initial reservoir storage conditions. It is found that the in- 
crease in system reliability will result in increase of water supply, while the change of initial reservoir storage will have negligible effects on water supply. The high and low water supplies in summer and winter correspond to the relevant demands in the two seasons.

Figure 3 shows the relationship between water release to the lower reach in different seasons under different reliability levels and initial reservoir storage conditions. It is indicated that the system reliability will have negligible impacts on the water release to the lower reach during winter, spring and summer seasons; however, it has significant effects in autumn. This fact is also revealed in the results of the factorial design experiments. In addition, the variations in the initial reservoir storage conditions lead to significant changes of water releases in winter and spring. Under high initial storage conditions, water release in winter is higher than that in spring.

Figure 4 shows the relationship between water release to the lower reach in different seasons and the initial reservoir storage under different reliability levels. It is indicated that system reliability will affect the water release in autumn. When the initial storage is less than 2.0 MCM, any of its variation will lead to significant effects in spring, but negligible impacts during winter, summer and autumn seasons. When the initial storage is greater than $2.0 \mathrm{MCM}$, the initial storage will have very significant effects in winter, but
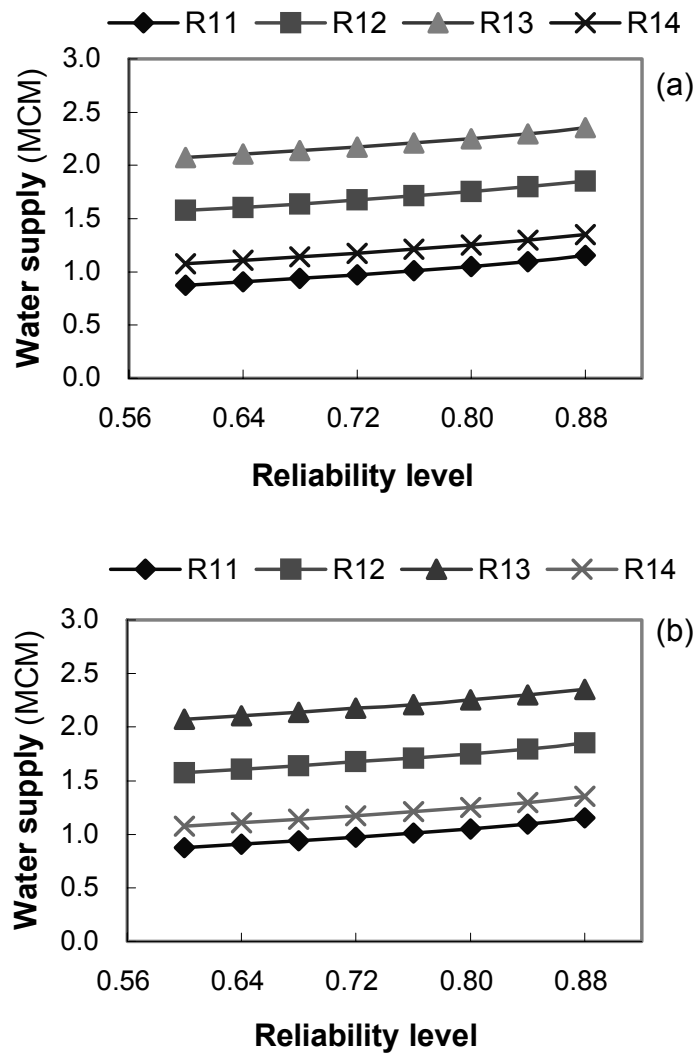

Figure 2. Optimal water supply to users versus system reliability level under (a) $\mathrm{S}_{0}=1.5$ and (b) $\mathrm{S}_{0}=4.5$. negligible impacts in spring, summer and autumn. These are also due to the fact that inflows, water demands, and flood and drought events vary among different seasons.

\section{Conclusions}

A methodology by integrating chance-constrained programming and factorial design is proposed to account for uncertainties in reservoir operation and management. A reservoir system that is responsible for supplying water to various users and releasing regulated flows to the lower reach is presented to illustrate the proposed method, and the operation objective is to minimize the total system cost for releasing water to the users and the lower reach. The related uncertain variables include inflows and water demands in different seasons in a year. The constraints include those of continuity, minimum release, minimum storage, flood and drought control, and water demand requirements under a variety of reliability levels. The impacts of system reliability and initial reservoir storage, as well as their interactions, are examined through a set of factorial design experiments, and the complex interrelationships among water releases, initial reservoir storage, and reliability level are examined through implementing the developed chance-constrained model based on a variety of system conditions. The results indicate that reasonable and informative outcomes have been generated. In general, this
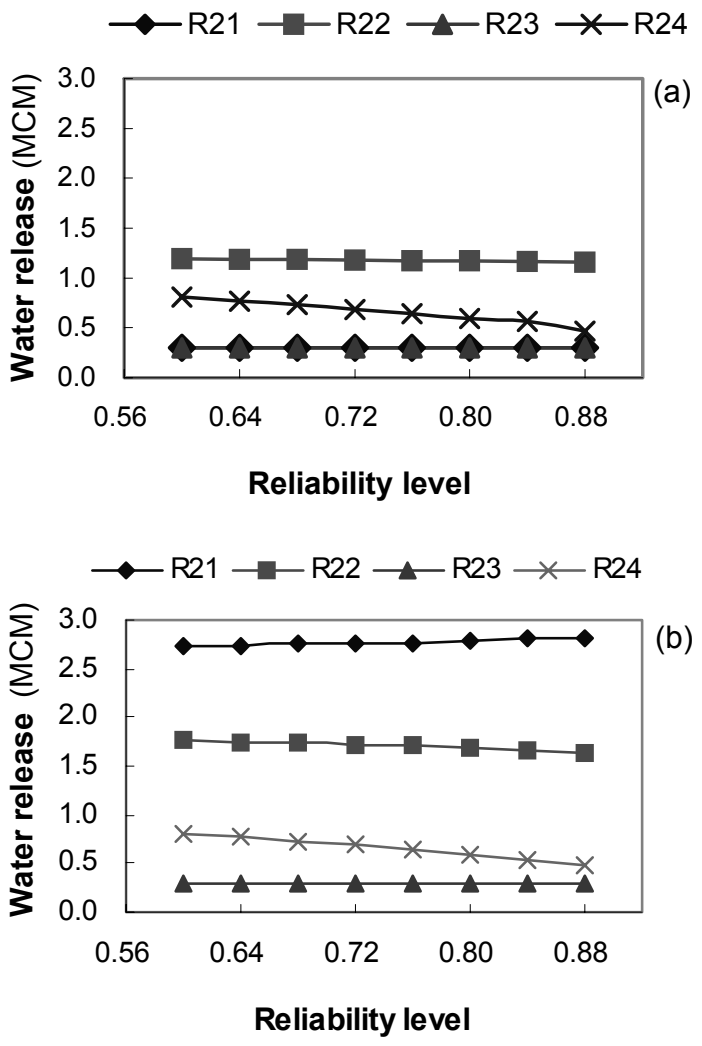

Figure 3. Optimal water release to the downstream versus system reliability level under (a) $\mathrm{S}_{0}=1.5$ and (b) $\mathrm{S}_{0}=4.5$. 

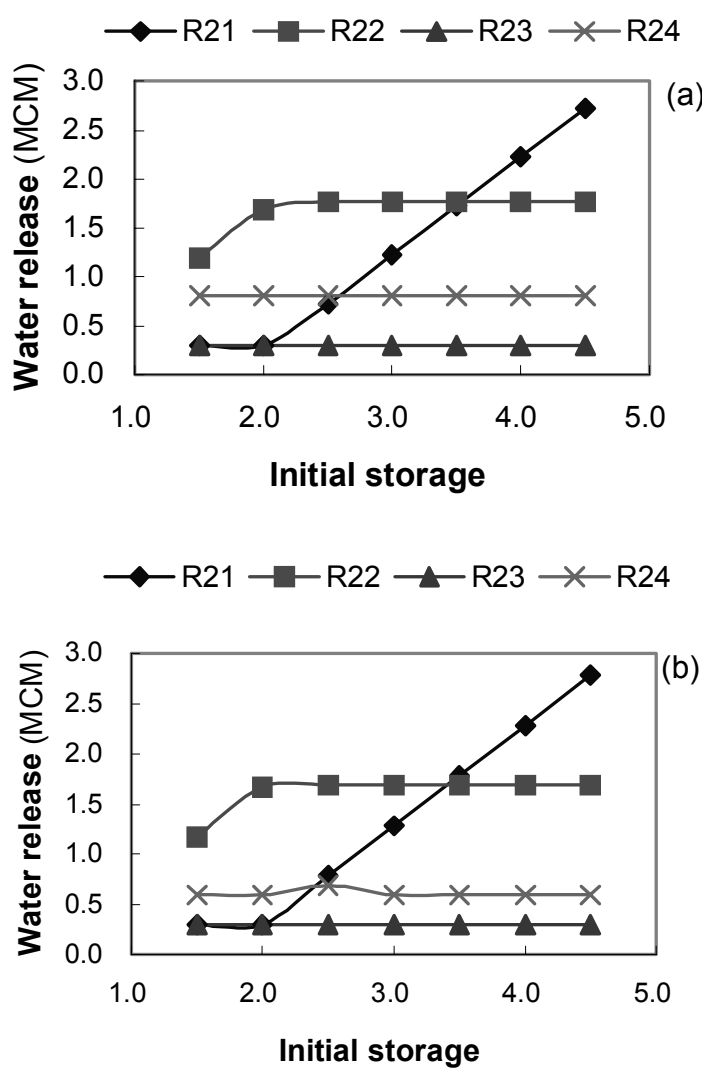

Figure 4. Optimal water release to the downstream versus initial reservoir storage under (a) $\alpha=0.60$ and (b) $\alpha=0.80$.

proposed approach offers an improved measure for reservoir operation and management under uncertainty by effectively relating the information quality of system variables to the reservoir operation decisions.

\section{References}

Box, G.E.P., Hunter W.G. and Hunter, J.S. (1978). Statistics for Experimenters, John Wiley \& Sons, New York, NY, USA.
Dos Santos, T.A. and Marino, M.A. (2002). Coupled reservoir operation-irrigation scheduling by dynamic programming. J. Irrig. Drain. Eng., 128(2), 63-73.

Duffuaa, S.O. (1991). A Chance-constrained model for the operation of the Aswan High Dam. Eng. Optimiz., 17(1/2), 109-122.

Hulsurkar, S., Biswal, M.P. and Sinha, S.B. (1997). Fuzzy programming approach to multi-objective stochastic linear programming problems. Fuzzy Sets \& Syst., 88(2), 173-181.

Jairaj, P.G. and Vedula, S. (2000). Multireservoir system optimization using fuzzy mathematical programming. Water Resour. Manage., 14(6), 457-472.

Jenkins, M.W. and Lund, J.R. (2000). Integrating yield and shortage management under multiple uncertainties. J. Water Resour. Plann. Manage., 126(5), 288-297.

Liu, B. (2001). Fuzzy random chance-constrained programming. IEEE Trans. Fuzzy Syst., 9(5), 713-720.

Morgan, D.R., Eheart, J.W. and Valocchi, A.J. (1993). Aquifer remediation design under uncertainty using a new chance constrained programming technique. Water Resour. Res., 29(3), 551-561.

Mohammed, W. (2000). Chance constrained fuzzy goal programming with right-hand side uniform random variable coefficients. Fuzzy Sets \& Syst., 109(1), 107-110.

Paudyal, G.N. and Das Gupta, A. (1990). A nonlinear chance constrained model for irrigation planning. Agric. Water Manage., 18(2), 87-100.

Rangarrajan, S. and Simonovic, S. (1999). The value of considering autocorrelation between inflows in the stochastic planning of water resource systems. Water Resour. Manage., 13(6), 427-442.

Ravikumar, V. and Venugopal, K. (1998). Optimal operation of south Indian irrigation systems. J. Water Resour. Plann. Manage., 124(5), 264-271.

Reznixek, K. and Cheng, T.C.E. (1991). Stochastic modelling of reservoir operations. Eur. J. Oper. Res., 50(3), 235-248.

Russell, S.O. and Campbell, P.F. (1996). Reservoir operating rules with fuzzy programming. J. Water Resour. Plann. Manage., 122(3), 165-170.

Umamahesh, N.V. and Sreenivasulu, P. (1997). Two-phase stochastic dynamic programming model for optimal operation of irrigation reservoir. Water Resour. Manage., 11(5), 395-406.

Wurbs, R.A. (1993). Reservoir-system simulation and optimization models. J. Water Resour. Plann. Manage., 119(4), 455-472.

Xu, Z.X., Ito, K., Liao, S. and Wang, L. (1997). Incorporating inflow uncertainty into risk assessment for reservoir operation. Stochastic Hydrol. Hydraul., 11(5), 433-448. 